\title{
Podoconiosis patients' willingness to pay for treatment services in Northwest Ethiopia: potential for cost recovery
}

\author{
Abreham Tamiru*, Girmay Tsegay', Moges Wubie', Molla Gedefaw², Sara Tomczyk ${ }^{3}$ and Fasil Tekola-Ayele ${ }^{4}$
}

\begin{abstract}
Background: Podoconiosis is non-filarial elephantiasis of the lower legs. It is more commonly found in tropical Africa, Central and South America, and northwest India. In Ethiopia, a few non-governmental organizations provide free treatment to podoconiosis patients, but sustainability of free treatment and scale-up of services to reach the huge unmet need is challenged by resource limitations. We aimed to determine podoconiosis patient's willingness to pay (WTP) for a treatment package (composed of deep cleaning of limbs with diluted antiseptic solution, soap, and water, bandaging, application of emollient on the skin, and provision of shoes), and factors associated with WTP in northwestern Ethiopia.
\end{abstract}

Methods: A cross-sectional study was conducted among randomly selected untreated podoconiosis patients $(n=393)$ in Baso Liben woreda, northwestern Ethiopia. The contingent valuation method was used with a pre-tested interviewer-administered questionnaire.

Results: The majority of podoconiosis patients (72.8\%) were willing to pay for treatment services. The median WTP amount was 64 Birr (US\$ 3.28) per person per year. More than one-third of patients (36.7\%) were willing to pay at least half of the full treatment cost and $76.2 \%$ were willing to pay at least half of the cost of shoes. A multivariate analysis showed that having a higher monthly income, being a woman, older age, being aware of the role of shoes to prevent podoconiosis, and possession of a functional radio were significantly associated with higher odds of WTP.

Conclusions: The considerable WTP estimates showed that podoconiosis treatment could improve sustainability and service utilization. A subsidized cost recovery scheme could reduce treatment costs and more feasibility integrate podoconiosis treatment service with other NTDs and the government's primary health care system.

Keywords: Willingness to pay (WTP), Podoconiosis, Neglected tropical disease, Health policy, Global health, Treatment, Contingent valuation method, Ethiopia

\section{Background}

Podoconiosis is a geo-chemical neglected tropical disease (NTD) affecting genetically susceptible people that have prolonged barefoot exposure to red clay soil. It leads to elephantiasis or swelling of the lower legs [1-4]. Podoconiosis is common in more than ten countries across tropical Africa, Central and South America and northwest India $[1,5,6]$. In endemic areas, podoconiosis-

\footnotetext{
* Correspondence: abrish80@gmail.com

'School of Public Health, College of Medicine and Health Sciences, Debre Markos University, P.O. Box 269, Debre Markos, Ethiopia

Full list of author information is available at the end of the article
}

affected patients and families suffer from extreme social stigmatization, physical disability, and economic impairment [7-9].

At the early clinical stages, podoconiosis can be treated using simple and effective measures: regular washing of feet with soap and water, application of emollient on the skin, elevation of the leg at night, compression therapy with elastic bandages, and regular use of footwear [10]. However, podoconiosis has been given little attention by health policy makers and implementing health institutions in endemic countries. For example, in Ethiopia, approximately one million patients are affected by podoconiosis, 
but only four percent have access to treatment services. These treatment services are provided by nongovernmental non-profit organizations [11]. In northern Ethiopia, most of the prevention and treatment services are provided nearly free of charge by the International Orthodox Christian Charities (IOCC) Podoconiosis Treatment and Prevention Project at six treatment clinics [12]. During the past three years, the demand for the treatment has increased and surpassed IOCC's resources. As a consequence, a large number of podoconiosis patients are on a waiting list. In western and southern Ethiopia, other donor-driven podoconiosis treatment programs have also faced financial challenges that have limited the sustainable provision of treatment and scale-up of services to meet the unmet needs [11].

Treatment cost-recovery options may add to the sustainability of treatment services and allow the integration of podoconiosis treatment in the primary health care system of government health facilities. In the present study, we determined the willingness to pay (WTP) of podoconiosis patients in northern Ethiopia to understand whether cost-recovery can be proposed as an option for sustainable treatment and control of podoconiosis.

\section{Methods}

\section{Study area}

The study was conducted in Baso Liben woreda (a government administrative region in Ethiopia, equivalent to a district), one of the 20 woredas in East Gojam Zone, northwestern Ethiopia. Its main town has an elevation of 2,211 meters above sea level. Baso Liben woreda's projected population size in the year 2013 was estimated to be 152,598 people, of which $95 \%$ live in rural areas and depend on subsistence farming for a living [13].

\section{Study design and sampling}

This was a cross-sectional institution-based study. The source of the study participants was podoconiosis patients in Baso Liben woreda on the waiting list of IOCC's Podoconiosis Treatment and Prevention Project $(\mathrm{n}=3,800)$. Using sample size calculation for a single population proportion and assuming a 95\% CI $(\mathrm{z}=1.96)$ for the margin of error to be no wider than $5 \%$, and a maximum single proportion (50\%), the minimum sample size becomes 384 individuals. We added 9 individuals on top of this for contingency. Adult podoconiosis patients were selected from the waiting list using the simple random sampling technique. First, the names of individuals on the waiting list at the IOCC Baso Liben treatment site were written on pieces of papers. Next, the pieces of papers were folded and mixed, and 393 study participants were randomly chosen to be included in the study.

\section{Data collection tool and procedures}

Data were collected using a structured questionnaire that had two parts. Part one included questions that assessed the demographic, clinical, shoe wearing, and socio-economic characteristics of the study participants. Part two assessed the study participants' WTP for podoconiosis treatment services. To assess WTP, the contingent valuation method (CVM) was used. CVM is a questionnaire-based method used to elicit the monetary value a person is willing to pay for a health care service [14]. First, a detailed explanation was given to all participants about the components of the treatment services provided by IOCC's Podoconiosis Treatment and Prevention Project, frequency of visits and schedules, types of health workers involved, and infrastructure of health facilities available for the treatment services. The treatment components include deep cleaning of limbs with diluted antiseptic solution, soap, and water, bandaging, application of emollient on the skin, and provision of shoes. Next, the respondents were asked a 'yes' or 'no' question about whether or not they would agree to pay for these treatment services. If the response was 'no', the respondents were asked the reason. If the response was 'yes', the respondents were asked an open-ended contingent valuation question about the maximum amount that they would be willing to pay for the treatment services per person per year. Following this openended question, every study participant was asked a series of binary (i.e. dichotomous choice) format questions based on the 'bidding game' method [14]. In the 'bidding game' method, respondents are asked whether or not they would be willing to pay a given amount and they are then asked follow-up questions about higher or lower amounts [14]. In this study, the series of questions was: (a) Are you willing to pay the full IOCC cost of treatment for podoconiosis (330 Birr or US\$ 16.92 per person per year)? (if no, go to b); (b) Are you willing to pay $3 / 4^{\text {th }}$ of the full cost (248 Birr or US\$ 12.72 per person per year)? (if no, go to c); (c) Are you willing to pay half of the full cost (165 Birr or US\$ 8.46 per person per year)? Shoes are the main component of podoconiosis treatment and prevention. Therefore, affected individuals were asked similar questions about WTP for shoes given other services are provided for free starting with the IOCC cost of shoe production for one person (250 Birr or US\$ 12.82). Eight nurses administered the questionnaires, and two public health officers supervised the data collection. Data collectors and supervisors were trained by the lead author of this paper (AT) for three days. Topics covered during the training included objectives of the study, interviewing techniques, and practical exercises. Pilot testing of the questionnaire was done before in a neighboring village the actual data collection. Data were collected from May to June 2013. 


\section{Data analysis}

The raw data were entered and cleaned in EPI INFO statistics program version 6.04 , and analyzed using the Statistical Package Social Sciences (SPSS) statistics program version 16.0. Descriptive statistics was done using summary statistics such as frequencies, average estimates (i.e., mean or median), and summary figures. ANOVA, univariate, and backward stepwise multivariate logistic regression analyses were performed to model factors associated with participants' willingness to pay. The level of significance was set to be 0.05 .

\section{Ethical considerations}

Ethical approval for the study was obtained from Debre Markos University in northern Ethiopia. Support letters were obtained from the regional and zonal health administrations. Informed consent was obtained from all study participants.

\section{Results}

\section{Socio-demographic and clinical characteristics of the} study participants

A total of 393 podoconiosis patients participated in the study (100\% response rate). The mean age of the study participants was 40.5 years (standard deviation [s.d.] = 13.5), $40.7 \%$ of the study participants were women, $69.5 \%$ were married, $86.5 \%$ were farmers, and $82.7 \%$ could not read and write. The mean family size per household was 5.2 individuals (s.d. $=2.6)$, and the majority $(64.1 \%)$ of the study participants perceived their household's socioeconomic status to be lower than the village average. Based on a clinical staging system for podoconiosis [15], 267 (67.9\%) participants had early clinical disease (i.e. stage I or II), and $126(32.1 \%)$ had advanced clinical disease (i.e., stage III, IV, or V). A total of 78 (19.8\%) study participants said that they had at least one podoconiosis-affected family member. Half of the study participants (55\% of women and $45.5 \%$ of men) were barefoot during the interview, and 135 study participants (34.4\%; $38.1 \%$ of women and $31.8 \%$ of men) said that they had never worn shoes (Table 1).

\section{Perceptions of the study participants about podoconiosis}

The majority $(65.7 \%)$ of the study participants believed that podoconiosis is caused by evil spirits or did not know the cause of podoconiosis. Only 34 (8.6\%) study participants mentioned that red clay soil has a causal association with the development of podoconiosis; the remaining $91.4 \%$ had misconception about the cause of podoconiosis. A total of $332(84.5 \%)$ study participants said that podoconiosis is preventable. Of these, most perceived that podoconiosis can be prevented by avoiding marriage with members of podoconiosis-affected families $(48.8 \%)$ or physical contact with podoconiosis
Table 1 Characteristics of the study participants $(n=393)$

\begin{tabular}{|c|c|c|}
\hline Characteristics & & Number (\%) \\
\hline \multirow[t]{2}{*}{ Sex } & Male & $233(59.3)$ \\
\hline & Female & $160(40.7)$ \\
\hline $\begin{array}{l}\text { Age in years } \\
\text { (mean, SD) }\end{array}$ & & $40.5(S D=13.5)$ \\
\hline \multirow[t]{4}{*}{ Occupation } & Farmer & $340(86.5)$ \\
\hline & Housewife & $17(4.3)$ \\
\hline & Private business & $22(5.6)$ \\
\hline & Other & $14(3.6)$ \\
\hline \multirow[t]{2}{*}{ Education } & Can read and write & $68(17.3)$ \\
\hline & Cannot read and write & $325(82.7)$ \\
\hline \multirow[t]{4}{*}{ Marital status } & Married & $273(69.5)$ \\
\hline & Divorced & $53(13.5)$ \\
\hline & Widowed & $34(8.7)$ \\
\hline & Single & $33(8.4)$ \\
\hline \multirow{5}{*}{$\begin{array}{l}\text { Monthly household } \\
\text { income in Birr* }(n=365) \text {, } \\
\text { median (range) }\end{array}$} & $100-180$ & $85(23.3)$ \\
\hline & $181-300$ & $92(25.2)$ \\
\hline & $301-500$ & $104(28.5)$ \\
\hline & $501-2500$ & $84(23.0)$ \\
\hline & $300(50-2502)$ & \\
\hline \multirow{3}{*}{$\begin{array}{l}\text { Patients' comparison } \\
\text { of their household } \\
\text { socio-economic status } \\
\text { with others in the } \\
\text { same village }\end{array}$} & Below average & $252(64.1)$ \\
\hline & Average & $129(32.8)$ \\
\hline & Above average & $12(3.1)$ \\
\hline \multirow[t]{5}{*}{ Clinical stage } & Stage I & $28(7.1)$ \\
\hline & Stage II & $239(60.8)$ \\
\hline & Stage III & $121(30.8)$ \\
\hline & Stage IV & $4(1.0)$ \\
\hline & Stage V & $1(0.3)$ \\
\hline $\begin{array}{l}\text { Have other } \\
\text { podoconiosis-affected } \\
\text { family member(s) }\end{array}$ & Yes & $78(19.8)$ \\
\hline
\end{tabular}

*Birr is the unit of currency in Ethiopia.

affected individuals (38\%). A total of 94 (28.3\%) and 92 (27.7\%) study participants mentioned that podoconiosis can be prevented by wearing shoes and washing feet with soap and water, respectively (Table 2).

\section{Willingness to pay for podoconiosis treatment services}

A total of $286(72.8 \%)$ study participants were willing to pay for podoconiosis treatment services. The study participants who chose not to pay $(\mathrm{n}=107 ; 27.2 \%)$ said that they could not afford to pay (93.4\%) or had low confidence in the effectiveness of the treatment (6.6\%). The mean household monthly income of study participants who were not willing to pay was lower than that of participants who were willing to pay (212.2 Birr vs. 455.65 Birr; $\mathrm{t}=-10.39, \mathrm{p}<0.0001)$. Through the open-ended 
Table 2 Perceptions and experiences about podoconiosis prevention

\begin{tabular}{|c|c|c|}
\hline Question & Response & Number (\%) \\
\hline \multirow{5}{*}{$\begin{array}{l}\text { What is the cause of } \\
\text { podoconiosis? }\end{array}$} & Evil Spirit & $178(45.3)$ \\
\hline & Insect & $15(3.8)$ \\
\hline & Soil/mud & $34(8.6)$ \\
\hline & Contact with dirty water & $6(1.5)$ \\
\hline & Do not know & $60(20.4)$ \\
\hline \multirow[t]{2}{*}{ Is podoconiosis preventable? } & Yes & $332(84.5)$ \\
\hline & No & $61(15.5)$ \\
\hline \multirow{4}{*}{$\begin{array}{l}\text { If the response to the above } \\
\text { question is 'Yes': How can } \\
\text { one prevent podoconiosis? }\end{array}$} & Wearing shoes & $94(28.3)$ \\
\hline & $\begin{array}{l}\text { Washing foot with soap } \\
\text { and water }\end{array}$ & $92(27.7)$ \\
\hline & $\begin{array}{l}\text { Avoiding marriage with } \\
\text { podoconiosis-affected } \\
\text { family members }\end{array}$ & $162(48.8)$ \\
\hline & $\begin{array}{l}\text { Avoiding contact with } \\
\text { podoconiosis patients }\end{array}$ & $126(38.0)$ \\
\hline
\end{tabular}

WTP question, we found that the median amount a person was willing to pay for the treatment services was 64 Birr (US\$ 3.28; range: 0-400 Birr or US\$ 0-20.51) per person per year. The demand for treatment services declined as price increased. This decline was slow between 10 Birr (US\$ 0.51) and 50 Birr (US\$ 2.56) after which it fell quickly. For example, $59 \%$ of the study participants had a WTP of at least 50 Birr (US\$2.56), whereas only 31.1\% had a WTP of at least 100 Birr (US\$ 5.13) (Figure 1). Over half of the individuals were willing to pay for other affected family members (Table 3 ).

Among the study participants who agreed to pay ( $\mathrm{n}=$ $286)$, some agreed to pay the full amount $(\mathrm{n}=44 ; 15.4 \%)$, three-fourths the amount $(n=14 ; 4.9 \%)$, or half the amount $(\mathrm{n}=47 ; 16.4 \%)$ of the current IOCC average treatment cost of 330 Birr (US\$ 16.92) per person per year. The cumulative proportions showed that 44 (15.4\%), 58 (20.3\%), and 105 (36.7\%) study participants were willing to pay $100 \%$, at least $75 \%$, and at least $50 \%$ of the average treatment cost of IOCC. When asked how much they would be willing to pay for shoes if other treatment supplies were free, some study participants were willing to pay the full amount $(\mathrm{n}=88 ; 30.8 \%)$, three-fourths the amount $(\mathrm{n}=24 ; 8.4 \%)$ or half the amount $(\mathrm{n}=106 ; 37.1 \%)$ of the current IOCC shoe production cost of $250 \mathrm{Birr}$ (US\$ 12.82) for one person. The cumulative proportions showed that 88 (30.8\%), 112 (39.2\%), and 218 (76.2\%) study participants were willing to pay $100 \%$, at least $75 \%$, and at least $50 \%$ of the shoe production cost if other treatment services are provided for free (Table 3).

\section{Factors associated with willingness to pay for podoconiosis treatment services}

Study participants who perceived their households to be poorer than the village average were willing to pay about half as much as those who considered their socioeconomic position average or better (ANOVA $\mathrm{F}=36.5, \mathrm{p}<0.0001$ ) (Figure 2). The multivariate analysis showed that being a woman, older age, having knowledge that podoconiosis can be prevented by wearing shoes, possession of a functional radio, higher income, recent history of paying for treatment services for other conditions, and production of wheat were associated with increased WTP for podoconiosis treatment services (Table 4). There was no statistically significant difference in WTP between patients with early and advanced clinical disease stages.

\section{Discussion}

In this first study to assess WTP for podoconiosis treatment services, we found that the majority $(72.8 \%)$ of the study participants in Baso Liben woreda were willing to pay. The proportion of individuals willing to pay for podoconiosis treatment was greater than the proportion of individuals willing to pay for injectable contraceptives in Tigray, northern Ethiopia (68\%) [16], but lower than the proportion willing to pay for insecticide-treated bed

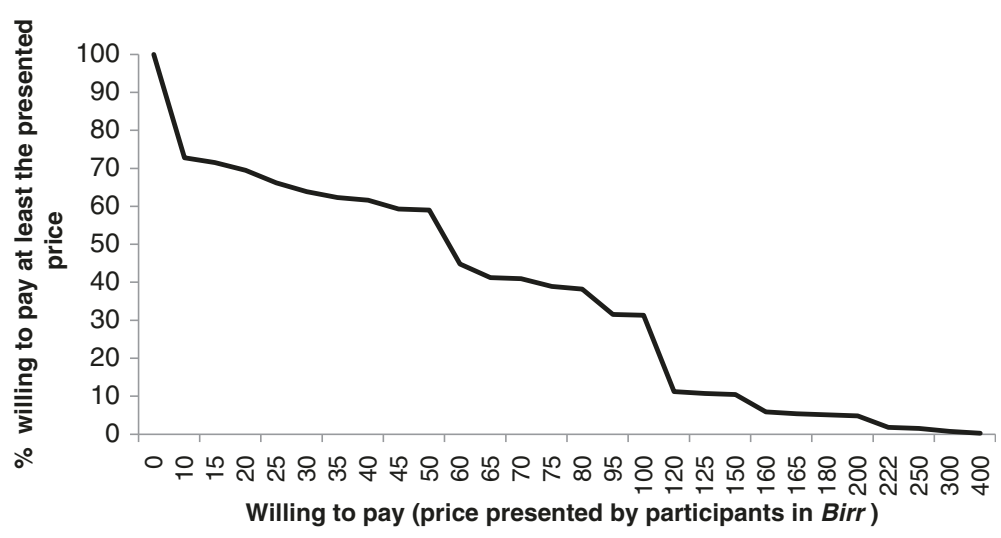

Figure 1 Demand curve for maximum willingness to pay for podoconiosis treatment services. 
Table 3 Willingness to pay for podoconiosis treatment services

\begin{tabular}{|c|c|c|c|}
\hline Willingness to pay characteristics & & Number (\%) & Cumulative number (\%) \\
\hline \multirow[t]{2}{*}{ Willing to pay for podoconiosis treatment services $(n=393)$ ? } & Yes & $286(72.8)$ & NA \\
\hline & No & $107(27.2)$ & NA \\
\hline \multirow{3}{*}{ Of those that agreed to pay $(n=286)$, individuals willing to pay the following: } & Full cost $\left(330\right.$ Birr $\left.^{*}\right)$ & $44(15.4)$ & $44(15.4)$ \\
\hline & $3 / 4^{\text {th }}$ of full cost (248 Birr) & $14(4.9)$ & $58(20.3)$ \\
\hline & $1 / 2$ of full cost $(165$ Birr) & $47(16.4)$ & $105(36.7)$ \\
\hline \multirow[t]{3}{*}{ Willing to pay for shoes if they get treatment supply free $(n=286)$} & Full cost (250 Birr) & $88(30.8)$ & $88(30.8)$ \\
\hline & $3 / 4^{\text {th }}$ of full cost $(188$ Birr $)$ & $24(8.4)$ & $112(39.2)$ \\
\hline & $1 / 2$ of full cost $(125$ Birr $)$ & $106(37.1)$ & $218(76.3)$ \\
\hline \multirow[t]{2}{*}{ Would you be willing to pay for other family members $(n=393)$ ? } & Yes & $218(55.5)$ & NA \\
\hline & No & $175(44.5)$ & NA \\
\hline
\end{tabular}

*Birr is the unit of currency in Ethiopia.

$\mathrm{NA}=$ not applicable.

nets in Arbaminch, southern Ethiopia (86\%) [17], and lipid-based nutrient supplements for young children in four urban sites of Ethiopia (96\%) [18]. These differences may be due to differences in socio-economic and demographic characteristics of the study populations. Individuals may also perceive malaria and malnutrition more severe with fatal consequences as compared to podoconiosis which is disfiguring, physically disabling, and psychologically and economically traumatizing but not fatal [6]. Despite these differences, the WTP for podoconiosis reported in this study is considerably high given the fact that podoconiosis is a neglected tropical disease that affects the poor, and the minimal level of awareness and wide misconceptions about podoconiosis in our study sample (91.4\%) and in a wider study population in northern Ethiopia $[19,20]$.

The proportion of respondents willing to pay the full price doubled from $15.4 \%$ to $36.7 \%$ when the fee requested dropped by half. Furthermore, the proportion of respondents willing to pay doubled from $36.7 \%$ that were willing to pay at least half IOCC's cost of full treatment package to $76.2 \%$ that were willing to pay at least half
IOCC's cost of shoes when other treatment services were given for free. The non-shoe component of podoconiosis treatment accounts 24\% (80 Birr) of IOCC's total treatment cost. Although full cost recovery or full user fee programs would not be feasible, we have found that incentives such as free service provision, however small, influence podoconiosis patients' WTP for treatment and utilization of the overall treatment package may be increased. This indicates that partial cost recovery programs could be introduced to increase coverage of treatment services and to make the integration of podoconiosis service in the government health system of Ethiopia more feasible.

Whether an individual was willing to pay for podoconiosis was strongly associated with the financial status of the household. Furthermore, individuals who were not willing to pay were members of households with half as much monthly income as compared to those that were willing to pay. Previous studies have shown that financial limitation was the primary barrier against consistent use of footwear among podoconiosis patients $[7,8]$. The study participants in our study appeared to have lower

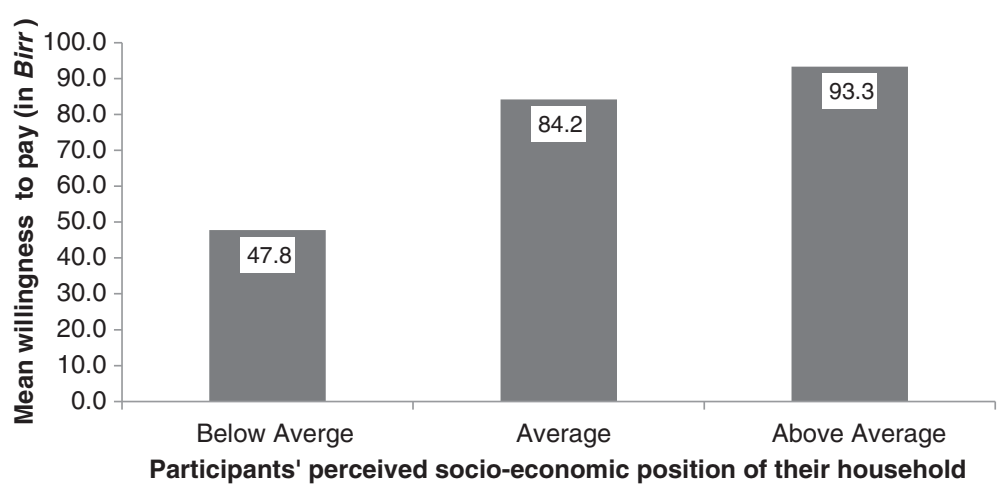

Figure 2 Perceived household socio-economic status and mean willingness to pay for podoconiosis treatment services. 
Table 4 Factors associated with willingness to pay for podoconiosis treatment services

\begin{tabular}{|c|c|c|c|c|c|}
\hline \multirow[t]{2}{*}{ Variable } & & \multicolumn{2}{|c|}{ Willing to pay } & \multirow{2}{*}{$\begin{array}{l}\text { Crude OR } \\
(95 \% \mathrm{Cl})\end{array}$} & \multirow{2}{*}{$\begin{array}{l}\text { Adjusted OR } \\
(95 \% \mathrm{Cl})\end{array}$} \\
\hline & & Yes & No & & \\
\hline \multirow[t]{2}{*}{ Sex } & Male & 175 & 58 & $1.33(0.85,2.08)$ & $0.43(0.19,0.96) ¥$ \\
\hline & Female & 111 & 59 & 1 & 1 \\
\hline \multirow[t]{2}{*}{ Educated } & No & 236 & 89 & $0.96(0.53,1.72)$ & $0.44(0.23,0.56)$ \\
\hline & Yes & 50 & 18 & 1 & 1 \\
\hline \multirow[t]{4}{*}{ Age in years } & $18-30$ & 85 & 31 & $0.69(0.35,1.34)$ & $0.36(0.13,0.51) ¥$ \\
\hline & $31-38$ & 56 & 26 & $0.54(0.27,1.09)$ & $0.21(0.07,0.64) ¥$ \\
\hline & $39-50$ & 77 & 33 & $0.58(0.29,1.14)$ & $0.36(0.16,0.71) ¥$ \\
\hline & $51-80$ & 68 & 17 & 1 & 1 \\
\hline \multirow[t]{4}{*}{ Monthly income in Birr } & 100-180 & 37 & 48 & $0.05(0.02,0.13)$ & $0.16(0.05,0.50) ¥$ \\
\hline & $181-300$ & 57 & 35 & $0.10(0.04,0.28)$ & $0.42(0.13,0.74) ¥$ \\
\hline & $301-500$ & 97 & 7 & $0.88(0.27,2.87)$ & $0.79(0.63,0.92) ¥$ \\
\hline & $501-2500$ & 79 & 5 & 1 & 1 \\
\hline \multirow[t]{2}{*}{ Believed that podoconiosis is preventable by wearing shoes } & Yes & 249 & 83 & $1.95(1.16,3.44)$ & $4.08(3.45,5.54) ¥$ \\
\hline & No & 37 & 24 & 1 & 1 \\
\hline \multirow[t]{2}{*}{ Paid for treatment during the past month } & Yes & 59 & 14 & $1.27(0.92,3.24)$ & $3.45(1.27,9.34) ¥$ \\
\hline & No & 227 & 93 & 1 & 1 \\
\hline \multirow[t]{2}{*}{ Family possessed a functional radio } & Yes & 97 & 12 & $4.06(2.12,7.77)$ & $4.87(1.89,12.55) ¥$ \\
\hline & No & 189 & 95 & 1 & 1 \\
\hline \multirow[t]{2}{*}{ Family harvested wheat } & Yes & 231 & 54 & $4.12(2.55,6.66)$ & $3.79(1.77,8.11) ¥$ \\
\hline & No & 55 & 55 & 1 & 1 \\
\hline \multirow[t]{2}{*}{ Wearing shoes during the interview } & Yes & 204 & 54 & $2.44(1.55,3.85)$ & $2.44(1.22,4.9) ¥$ \\
\hline & No & 82 & 53 & 1 & 1 \\
\hline
\end{tabular}

$\mathrm{OR}=$ odds ratio, $\mathrm{Cl}=$ confidence interval, $\mathrm{Ref}=$ reference.

*Adjustment was made for: sex, education, age, monthly income, belief on preventability of podoconiosis, previous history of paying for treatment service, possession of goat, radio, and donkey, wheat harvesting, wearing shoes during interview.

$¥ \mathrm{P}$-value is $<0.05$.

socioeconomic status because the majority of the respondents (64.1\%) perceived that they were poorer than the village average, and half of the study participants were barefoot during the interview. Moreover, approximately twenty percent of the study participants reported at least one additional podoconiosis-affected household member, which can lower the economic productivity of households due to the morbidity from acute adenolymphangitis (ALA: hot, tender, painful symptoms in the lower legs) experienced by affected individuals as reported by previous studies in northern Ethiopia [19,20].

Several factors influenced WTP of podoconiosis patients. Factors that were associated with increased WTP can be generalized under four categories: (i) higher socio-economic status; (ii) older age, (iii) female sex, and (iv) more awareness about podoconiosis and modern health care. First, the positive association between higher socio-economic status and WTP in our study is supported by several other studies, showing that people's WTP behavior parallels their ability to pay [21]. Similar findings have been reported in previous studies conducted in
Ethiopia on WTP for injectable contraceptives [16] and insecticide-treated bed nets [17]. Second, older podoconiosis patients had greater WTP. This may be because the onset of podoconiosis is usually in the third decade of life and the disease advances with age urging patients to seek health care due to multiple episodes of ALA, limitations of physical activity, morbidity, and pain [19,20,22-24]. In addition, a study in southern Ethiopia has shown that because of financial resource barriers in the household, shoes (the main components of podoconiosis treatment and prevention) are often purchased for older household members first rather than for children [25]. Third, our finding of WTP by more women as compared to men may be because more women experience ALA including more frequent episodes and more bed days per episode [23]. In the present study, more women than men were barefoot during the interview ( $55 \%$ vs. $45.5 \%$ ) and more women had never worn shoes $(38.1 \%$ vs. $31.8 \%$ ) consistent with previous studies showing that women possessed fewer means to prevent podoconiosis compared to men [6,14], resulting in a higher demand 
for treatment service. Moreover, stigmatization and poor marriage prospects for podoconiosis affected women $[5,8]$ may be additional social factors that motivate women to be willing to pay more for treatment than men. Fourth, factors such as the possession of a functional radio and previous experience of treatment seeking for other illnesses could enhance awareness about modern health care and this has also been found to be associated with increased odds of WTP for insecticide-treated bed nets [17].

The study participants' median WTP based on the open-ended question was approximately twenty percent of IOCC's total treatment cost and a quarter of IOCC's shoe production cost. The WTP amount declined only slightly until after the total cost was $15 \%$ of IOCC's total treatment cost. These findings show new opportunities to introduce cost-recovery strategies in podoconiosis treatment programs. The price that is both affordable by most podoconiosis-affected households and optimal for cost-recovery should be assessed in program planning.

We acknowledge that there are some limitations to this study. The sample was selected from the treatment program waiting list which may have biased results. For example study participants prior knowledge of IOCC's highly subsidized podoconiosis treatment program services may have made them less willing to pay which would have underestimated the WTP amount. An additional limitation could be related to the representativeness of the results. WTP could vary by regional cultures and seasonally, so more research is needed to explore WTP which could be used in the national NTD programming and policy planning. The findings of this study needs to be validated using qualitative study methods, in socioculturally and economically diverse areas in Ethiopia, and at different seasons of the year because individuals' WTP varies with season as the majority of the study participants are farmers. Moreover, we have not assessed the test-retest reliability of the CVM due to resource and time constraints.

This study can serve as a foundation for future studies to set a price threshold for podoconiosis treatment services in both governmental and non-governmental facilities. For podoconiosis affected households that are not able to afford and not willing to pay, selective fee waiver certification could be introduced. A fee-waiver and exemption system is currently institutionalized in Ethiopia's government health service institutions for essential health care services [26], and this can be adapted for podoconiosis treatment.

\section{Conclusions}

This study showed a significant potential for introducing a cost-recovery system that could increase podoconiosis treatment service utilization and reduce the backlog of patients in the waiting list of IOCC due to inadequacy of resources. In Ethiopia, less than four percent of estimated podoconiosis patients have access to treatment [11]. Therefore, the promotion of self-financing could enhance the sustainability of treatment in podoconiosis programs or integrated initiatives such as morbidity management with filarial lymphedema. A subsidized costrecovery scheme could reduced treatment costs and more feasibly integrate podoconiosis treatment services with other NTDs and the government's primary health care system.

\section{Abbreviations \\ ALA: adenolymphangitis; CVM: Contingent valuation method; IOCC: International Orthodox Christian Charities; NTD: Neglected tropical disease; OR: Odds ratio; s.d.: Standard deviation; WTP: Willingness to pay.}

\section{Competing interests}

The authors declare that they have no competing interests.

\section{Authors' contributions}

FTA conceived the study. AT, FTA, MG, ST, and MW designed the study. AT supervised the fieldwork. AT, GT, and FTA analyzed the study. AT and FTA drafted the manuscript, and all authors interpreted the findings, and critically reviewed the manuscript for substantial intellectual content. All authors approved the final version of the manuscript.

\section{Acknowledgements}

We thank the staff of the International Orthodox Christian Charities Podoconiosis Project in Ethiopia for coordinating the study and Professor Gail Davey for the financial support of the fieldwork through the Welcome Trust grant (grant number 095956).

\section{Author details}

${ }^{1}$ School of Public Health, College of Medicine and Health Sciences, Debre Markos University, P.O. Box 269, Debre Markos, Ethiopia. ${ }^{2}$ GAMBY Medical Sciences College, P.O. Box 209, Bahir Dar, Ethiopia. ${ }^{3}$ Institute of Tropical Medicine, Antwerp, Belgium. ${ }^{4}$ Center for Research on Genomics and Global Health, National Human Genome Research Institute, National Institutes of Health, 20892 Bethesda, MD, USA.

Received: 26 December 2013 Accepted: 11 March 2014 Published: 19 March 2014

\section{References}

1. Price E: Podoconiosis: Non-Filarial Elephantiasis. Oxford: Oxford Medical; 1990.

2. Price EW: A possible genetic factor in non-filarial elephantiasis of the lower legs. Ethiop Med J 1972, 10(3):87-93.

3. Davey G, Gebrehanna E, Adeyemo A, Rotimi C, Newport M, Desta K: Podoconiosis: a tropical model for gene-environment interactions? Trans R Soc Trop Med Hyg 2007, 101(1):91-96.

4. Tekola Ayele F, Adeyemo A, Finan C, Hailu E, Sinnott P, Burlinson ND, Aseffa A, Rotimi CN, Newport MJ, Davey G: HLA class II locus and susceptibility to podoconiosis. N Engl J Med 2012, 366(13):1200-1208.

5. Wanji S, Tendongfor N, Esum M, Che JN, Mand S, Tanga Mbi C, Enyong P, Hoerauf A: Elephantiasis of non-filarial origin (podoconiosis) in the highlands of north-western Cameroon. Ann Trop Med Parasitol 2008, 102(6):529-540.

6. Davey G, Tekola F, Newport MJ: Podoconiosis: non-infectious geochemical elephantiasis. Trans R Soc Trop Med Hyg 2007, 101(12):1175-1180.

7. Tekola F, Mariam DH, Davey G: Economic costs of endemic non-filarial elephantiasis in Wolaita Zone, Ethiopia. Trop Med Int Health 2006, 11(7):1136-1144.

8. Yakob B, Deribe K, Davey G: High levels of misconceptions and stigma in a community highly endemic for podoconiosis in southern Ethiopia. Trans R Soc Trop Med Hyg 2008, 102(5):439-444.

9. Tekola F, Bull S, Farsides B, Newport MJ, Adeyemo A, Rotimi CN, Davey G: Impact of social stigma on the process of obtaining informed consent 
for genetic research on podoconiosis: a qualitative study. BMC Med Ethics 2009, 10:13.

10. Sikorski C, Ashine M, Zeleke Z, Davey G: Effectiveness of a simple lymphoedema treatment regimen in podoconiosis management in southern ethiopia: one year follow-up. PLoS Negl Trop Dis 2010, 4(11):e902.

11. Tekola Ayele F, Adeyemo A, Rotimi CN: Using a "genomics tool" to develop disease prevention strategy in a low-income setting: lessons from the podoconiosis research project. J Community Genet 2012. 3(4):303-309.

12. Tomczyk S, Tamiru A, Davey G: Addressing the neglected tropical disease podoconiosis in Northern Ethiopia: lessons learned from a new community podoconiosis program. PLOS Negl Trop Dis 2012, 6(3):e1560

13. CSA \& ORC Macro: The 2007 Population and Housing Census of Ethiopia. 2007. Addis Ababa: CSA.

14. Klose T: The contingent valuation method in health care. Health Policy 1999, 47(2):97-123.

15. Tekola F, Ayele Z, Mariam DH, Fuller C, Davey G: Development and testing of a de novo clinical staging system for podoconiosis (endemic non-filarial elephantiasis). Trop Med Int Health 2008, 13(10):1277-1283.

16. Prata N, Bell S, Weidert K, Gessessew A: Potential for cost recovery: women's willingness to pay for injectable contraceptives in Tigray, Ethiopia. PLoS One 2013, 8(5):e64032.

17. Gebresilassie FE, Mariam DH: Factors influencing people's willingness-tobuy insecticide-treated bednets in Arbaminch Zuria District, southern Ethiopia. J Health Popul Nutr 2011, 29(3):200-206.

18. Segre J, Winnard K, Abrha TH, Abebe Y, Shilane D, Lapping K: Willingness to pay for lipid-based nutrient supplements for young children in four urban sites of Ethiopia. Matern Child Nutr 2012, 6:81-93.

19. Molla YB, Tomczyk S, Amberbir T, Tamiru A, Davey G: Podoconiosis in East and West Gojam Zones, Northern Ethiopia. PLoS Negl Trop Dis 2012, 6(7):e1744.

20. Molla YB, Tomczyk S, Amberbir T, Tamiru A, Davey G: Patients' perceptions of podoconiosis causes, prevention and consequences in East and West Gojam, Northern Ethiopia. BMC Public Health 2012, 12:828.

21. Sherrod D, Downs R: Environmental determinants of altruism: the effects of stimulus overload and perceived control on helping. J Exp Soc Psychol 1974, 10:468-479.

22. Alemu G, Tekola Ayele F, Daniel T, Ahrens C, Davey G: Burden of podoconiosis in poor rural communities in Gulliso woreda, West Ethiopia. PLoS Negl Trop Dis 2011, 5(6):e1 184.

23. Tekola Ayele F, Alemu G, Davey G, Ahrens C: Community-based survey of podoconiosis in Bedele Zuria woreda, West Ethiopia. Int Health 2013, 5(2):119-125.

24. Geshere Oli G, Tekola Ayele F, Petros B: Parasitological, serological and clinical evidence for high prevalence of podoconiosis (non-filarial elephantiasis) in Midakegn District, Central Ethiopia. Trop Med Int Health 2012, 17(6):722-726.

25. Ayode D, McBride CM, de Heer HD, Watanabe E, Gebreyesus T, Tora A Tadele G, Davey G: A qualitative study exploring barriers related to use of footwear in rural highland ethiopia: implications for neglected tropical disease control. PLoS Negl Trop Dis 2013, 7(4):e2199.

26. USAID: Health Care Financing Reforem in Ethiopia: Improving Quality and Equity. In Health Systems 20/20 Project. USAID; 2012,2(2):1-12.

\section{Submit your next manuscript to BioMed Central and take full advantage of:}

- Convenient online submission

- Thorough peer review

- No space constraints or color figure charges

- Immediate publication on acceptance

- Inclusion in PubMed, CAS, Scopus and Google Scholar

- Research which is freely available for redistribution

Submit your manuscript at www.biomedcentral.com/submit 